TRAÇANDO PERCURSOS DA FONOLOGIA

\title{
MAPPING PHONOLOGY PATHS
}

\author{
Gisela Collischonn ${ }^{1}$
}

RESUMO: Partindo do olhar da fonologia, apresentamos uma retrospectiva da nossa área, focalizando o desenvolvimento de trabalhos sobre a língua portuguesa, nas variedades faladas no Brasil, enfocando tanto modelos teóricos que foram se sucedendo quanto os resultados a que chegamos nestes 25 anos e as perspectivas que se colocam daqui para frente.

ABSTRACT: From the phonological viewpoint, we present a retrospect of our field, focusing on the development of researches on the Portuguese language, dealing with the varieties spoken in Brazil. Our paper considers the theoretical models that have been proposed and the results of research on Portuguese from the last 25 years, and identifies some of the perspectives for developments from here on.

Palavras-chave: fonologia - modelos teóricos - língua portuguesa

Keywords: phonology - theoretical models - Portuguese language

\footnotetext{
${ }^{1}$ Doutora em Lingüística Aplicada pela Pontifícia Universidade Católica do Rio Grande do Sul, Professora Associada do Instituto de Letras da UFRGS, Porto Alegre; atua no Programa de Pós-Graduação em Letras na área de Teoria e Análise Lingüística e é pesquisadora do CNPQ; e-mail: giselac@ via-rs.net.
} 


\section{INTRODUÇÃO}

O GT de Fonética e Fonologia foi um dos primeiros a serem criados no âmbito da ANPOLL e tem buscado, ao longo destes 25 anos, garantir a integração entre pesquisadores das duas áreas, bem como incentivar o contato com áreas afins, como a Dialetologia, a Sociolingüística, a Psicolingüística, entre outras. Apesar da estreita aproximação, fonologia e fonética são, sob muitas perspectivas, disciplinas distintas. Enquanto a fonologia se ocupa das representações simbólicas, cujo alfabeto é, em geral, considerado como constituído de unidades discretas, a fonética tem como foco os objetos sonoros no espaço tridimensional e no tempo. Em consequência, as metodologias empregadas para o levantamento dos dados e as perguntas que se colocam são muito diferentes. Entretanto, historicamente as duas disciplinas constituem campos estreitamente conexos: a fonética é considerada uma disciplina aliada da fonologia, como os estudos de léxico e de morfologia também são; além disso, as fronteiras entre uma disciplina e outra são continuamente reformuladas, dependendo do modelo teórico proposto. Na organização dos nossos cursos de Letras e de pós-graduação, as duas áreas estão sempre associadas, muitas vezes dividindo programas de uma mesma disciplina; essa realidade refletese também nos programas de concurso para docentes e na alocação de recursos pelas agências de fomento. Por isso, é natural que, na organização dos GTs da ANPOLL, os dois campos fossem reunidos num mesmo 
grupo. Mais recentemente, a partir do final dos anos 80 , muitos linguistas têm se esforçado no desenvolvimento de um programa de pesquisas mais cooperativo entre foneticistas e fonológos, buscando enfatizar mais as conexões que existem do que as diferenças que separam as duas áreas.

Isso posto, convém destacar que o relato que faço aqui é, por força da minha formação, naturalmente perspectivado pela fonologia. Embora não se pretenda a defesa de um olhar teórico-metodológico particular, é evidente que, nos percursos que busco rastrear nas próximas linhas, a ênfase cairá, inevitavelmente, na Fonologia, e numa particular linha de investigação dessa disciplina, em função da minha formação e daquilo que pude observar ao longo das últimas duas décadas, desde os meus estudos de pós-graduação. Com isto, quero ressalvar que este relato não se pretende exaustivo quanto a abordagens teóricas e trabalhos descritivos realizados na área.

Tentando responder à pergunta sobre para onde nos leva o desenvolvimento da fonologia, Goldsmith (2009) propõe pensar a disciplina como constituída de quatro elementos: teoria, dados, métodos e miolo (kernels). As teorias vão se sucedendo, uma proposta podendo suplantar completamente a proposta anterior. Dados e métodos são razoavelmente constantes, embora não totalmente independentes das teorias. O 'miolo' é constituído pelos resultados das pesquisas, é o conhecimento acumulado que temos sobre coisas como a estrutura dos inventários sonoros, a harmonia vocálica, a estrutura das sílabas e dos pés, os sistemas de acento, os sistemas de tom, e assim por diante. Esses resultados constituem a base sobre a qual as teorias que vão sendo propostas são avaliadas. Para Goldsmith, quando se olha muito de perto para os embates teóricos, pode parecer que a disciplina não avance; pode ser que as rupturas entre um modelo teórico e outro pareçam tão grandes que não se vislumbre continuidade ou cumulatividade da disciplina; somente quando olhamos para o miolo, é que podemos ver que a continuidade e a cumulatividade de fato existem. O miolo é também aquilo que sabemos sobre uma determinada língua, independente da perspectiva teórica. Partindo desta conceituação, vamos buscar aqui uma retrospectiva da nossa área, focalizando o desenvolvimento de trabalhos sobre a língua portuguesa, nas variedades faladas no Brasil, enfocando não tanto as teorias, mas, preferencialmente, os resultados que se acumularam nestes 25 anos e as perspectivas que se colocam daqui para frente. Antes desse detalhamento, porém, consideramos importante relembrar alguns marcos importantes no desenvolvimento de modelos teóricos nos últimos 25 anos e seu impacto no Brasil. 


\section{AS TEORIAS FONOLÓGICAS DOS ÚLTIMOS 25 ANOS E SEU IMPACTO NO BRASIL}

O ano de 1985, de certa forma, é um marco na história das idéias em fonologia. Neste ano, um volume hoje clássico da revista Phonology Yearbook, precursora da revista Phonology, foi publicado com artigos de Clements, Kiparsky, Mohanan, Kaisse e Shaw, entre outros. O artigo de Clements apresenta a geometria de traços. A fonologia autossegmental se consolidava pela aplicação - aos traços internos - das mesmas propriedades de autonomia e dependência parcial anteriormente atribuídas ao tom (Leben, 1973; Goldsmith, 1976) e a fenômenos assimilatórios de longa distância, como nasalização e harmonia vocálica (Clements, 1976). Outros trabalhos importantes do período são Prosodic Phonology, (Nespor e Vogel 1986), que propõe a existência de constituintes prosódicos com propriedades independentes da estrutura morfossintática e regidos por princípios universais; e CV Phonology (Clements e Keyser, 1983), teoria da estrutura silábica na qual princípios gerais e universais adquirem o papel de atribuir estrutura silábica às seqüências fonológicas. Com relação ao acento, o ano de 1987 traria a publicação de Halle e Vergnaud (1987), um ensaio detalhado sobre como as línguas poderiam variar em termos de localização do acento lexical e de acentos secundários. Todas essas contribuições teóricas propunham novos recursos representacionais, os quais enriqueciam as possibilidades descritivas da fonologia gerativa, ao mesmo tempo em que buscavam dar respostas objetivas sobre as possibilidades de variação entre as línguas, através da postulação de princípios e parâmetros que mantinham as novas possibilidades representacionais dentro de limites determinados. O período também vê correntes de investigação que buscam tratar os fenômenos fonológicos a partir de perspectivas desenvolvidas na sintaxe, especialmente os modelos de fonologia de governo (Kaye, Lowenstamm e Vergnaud 1988) e de fonologia da dependência (Anderson e Ewen 1987). Foi também nesse período que novas abordagens da entonação ganharam impulso, a partir da tese de Pierrehumbert (1980), a qual desenvolve ferramentas para a representação fonológica da entonação nos moldes das representações autossegmentais para o tom. O período é caracterizado por um esforço muito grande no desenvolvimento de ferramentas que permitam descrever com maior acurácia os fenômenos segmentais e suprassegmentais observados. Ao mesmo tempo, não se perde de vista a busca por uma unificação entre as diversas abordagens, em nome da parcimônia teórica; entretanto, essa preocupação fica sempre subordinada à primeira, ou seja, à 
busca dos construtos teóricos mais adequados para a descrição das línguas, com uma atenção especial às línguas africanas.

No Brasil, ainda predominava a preocupação em descrever regras fonológicas e estrutura subjacente dos morfemas no molde da fonologia gerativa clássica, tendo como referência os trabalhos de Lopez (1979) e Mateus(1975/1982). Aos poucos, as teorias que estavam sendo desenvolvidas nos EUA e na Europa começam a ser difundidas aqui através de textos, como Syllable Structure and Stress in Spanish, de James Harris (Harris, 1983), no qual se adotam conceitos da fonologia métrica e da fonologia não-linear para a análise do espanhol.

No entanto, as teorias fonológicas dos anos 80 somente aportariam com força a partir do início dos anos 90 . A nova década observa o desenvolvimento de trabalhos que buscam a aplicação das novas unidades de análise aos dados do português. Leda Bisol publica análises do acento do português pela fonologia métrica, dos ditongos pela geometria de traços e do sândi e da epêntese pela teoria silábica (respectivamente, Bisol, 1992, 1994, 1996, 1999). Wetzels (1992) adota as ferramentas da geometria, de desligamento de traços e especificação default, para a interpretação da neutralização das distinções de altura das vogais em português. Hora (1993) utiliza a geometria na representação da palatalização de /t,d/ e Hernandorena (1994, 1995) na interpretação das substituições segmentais realizadas por crianças em fase de aquisição da língua materna. A fonologia de governo também suscitou trabalhos sobre a estrutura silábica do português (Magalhães, 1994 Cristófaro-Silva, 1996). Estudos sobre o papel da estrutura prosódica na fonologia do português (Tenani, 2000, Sândalo e Truckenbrodt, 2004) ainda demorariam mais um pouco, surgindo por influência das pesquisas realizadas sobre o português europeu por Frota (1998) e Vigário (2003).

É bom lembrar, porém, que, um pouco antes desse período, trabalhos de descrição do português falado haviam adquirido importância, a partir do surgimento das fitas cassete e de gravadores portáteis e do desenvolvimento de programas de análise estatística de dados (como o programa VARBRUL, Sankoff, 1988; Rousseau; Sankoff, 1978; Pintzuk, 1988), o que significou a análise mais rápida e em maior escala do material coletado, uma verdadeira revolução metodológica. ${ }^{2}$ A realização de pesquisas de caráter variacionista

\footnotetext{
${ }^{2} \mathrm{Na}$ atualidade, vive-se novamente um momento parecido com a popularização dos programas de análise acústica: PRAAT (Boersma; Weenink, 1996), WaveSurfer (Beskow; Sjölander, 2006) entre outros, o que permite que novas dimensões da fala, antes somente observáveis em raros laboratórios de fonética, estejam acessíveis aos pesquisadores.
} 
(nos moldes de Labov, 1966, 1994) traz metodologia experimental nova para as pesquisas sobre língua falada e, de certa forma, traz conseqüências para a nossa concepção sobre as fronteiras entre a fonética e a fonologia. Embora a variação social também seja considerada, o foco principal não são as diferentes variedades, mas os fenômenos fonológicos analisados e sua taxa de aplicação em relação a diferentes condicionadores lingüísticos. Acredito ser essa uma das características do desenvolvimento da fonologia no Brasil nos anos 90, alimentada por estudos empíricos baseados na metodologia variacionista e por concepções e ferramentas descritivas fornecidas pela chamada fonologia não-linear.

Também não deve ser esquecido o diálogo que se trava entre estes estudos e pesquisas de cunho dialetológico que vão buscando aos poucos abranger todos os rincões do Brasil e cujos dados, disponibilizados em atlas, se tornam acessíveis aos demais pesquisadores. Uma das consequências dessa particularidade brasileira da fonologia, de fertilização mútua com pesquisadores voltados para a variação e para a dialetologia, é que não se adota aqui a idéia - muito difundida em outros lugares - de que os fenômenos variáveis, não-categóricos, sejam automaticamente excluídos da pesquisa fonológica.

Outra área em que os estudos empíricos se desenvolveram à luz da fonologia não-linear foi a de aquisição da fonologia. Muito importante foi a organização de corpora sobre aquisição de língua falada, com grande quantidade de informantes e de dados (Lamprecht, 2004). A análise cuidadosa destes dados à luz de hipóteses fornecidas pela fonologia teórica permitiu um entendimento maior sobre vários aspectos da fonologia do português, bem como de tipologias e de universais implicacionais.

Já na segunda metade dos anos 90, é proposta a Teoria da Otimalidade (OT), que, entre outras coisas, pode ser entendida como uma reação à riqueza de recursos descritivos da fonologia não-linear, no sentido de restringir o seu potencial gerador de gramáticas distintas. A OT propõe reduzir mecanismos - tais como regras, níveis derivacionais, condições, princípios e parâmetros - a um só mecanismo: a interação entre restrições. Ou seja, as restrições executam o papel que na fonologia derivacional era realizado tanto pelas regras quanto por condições estáticas, tais como condições de boa-formação e filtros. As restrições, que são universais, atuam de forma específica em cada língua pelo ranking que existe entre elas.

Um outro movimento surgido nos anos 90, mas com uma preocupação diametralmente distinta da dos proponentes da OT, é o que busca ligar 
a fonologia aos métodos da experimentação psicológica; esta tendência inclui a fonologia de laboratório (Kingston; Beckman, 1990) e a fonologia articulatória (Browman e Goldstein 1989, 1992).

Enquanto, na OT, as explicações são buscadas em razões internas da língua e num conjunto inato de restrições, as explicações da fonologia de laboratório baseiam-se mais em razões externas, no controle motor e na percepção da fala. A fonologia de laboratório tem permitido a testagem de determinadas predições dos modelos teóricos e, em muitos aspectos, tem revelado as limitações das concepções categóricas em fonologia. Por exemplo, as nossas crenças a respeito de processos que envolvem neutralização de contrastes frequentemente são desafiadas por experimentos que indicam que os falantes podem estar percebendo diferenças entre formas supostamente neutralizadas, até mesmo em processos que envolvam o aparente apagamento de segmentos (Dinnsen, 1985; Port e Crawford, 1989). Em muitos casos, as análises mostram que o processo neutralizador se aplica, mas são mantidas determinadas pistas fonéticas de maneira que a neutralização entre palavras não acontece de fato (por exemplo, para muitos falantes do português brasileiro, ocorre o apagamento de $\mathbf{r}$ em final de substantivos, como em calor, mas a forma não fica idêntica à forma verbal calou, na qual a semivogal foi apagada [ka'lo]). Podemos então falar em neutralização de contrastes segmentais que não se realizam como neutralização de palavras.

A introdução de novas técnicas de experimentação é a grande contribuição da fonologia de laboratório, mas ela também permitiu uma maior abertura para a consideração de outras áreas da linguagem humana relacionadas à estrutura fonológica. No que se refere à freqüência, uma corrente bastante forte defende que cada realização de uma palavra pode ficar estocada na memória do falante e que as formas mais freqüentes neste estoque mental influenciarão de forma mais significativa a estrutura das representações sonoras. Essa seria a explicação de por que palavras ouvidas mais frequentemente podem apressar determinados processos, enquanto palavras menos freqüentes, de certa forma, os retardam (Bybee, 2001).

Neste contexto, é proposta a teoria dos exemplares, que assume que os falantes abstraem os padrões fonológicos das realizações que escutam e que são preservadas com rico detalhamento fonético em sua memória. A partir das formas armazenadas, os falantes apreendem as freqüências de distribuição das realizações fonéticas particulares; essas distribuições ficam 
armazenadas na memória de longo-termo e estão sujeitas a atualizações constantes (Pierrehumbert, 2002). ${ }^{3}$

Esses modelos parecem desafiar a perspectiva tradicional da fonologia gerativa de representações subjacentes abstratas, das quais toda informação redundante foi eliminada. Entretanto, é bem possível que tanto as representações abstratas quanto as representações mais detalhadas façam parte do conhecimento que o falante tem da sua língua. Há fenômenos que tipicamente enfatizam o papel da gradualidade fonética, como são muitos dos casos de lenição e de processos assimilatórios de natureza coarticulatória; há, no entanto, outros que não se prestam tão bem a uma análise desse tipo, como os casos de harmonia vocálica, por exemplo. O acento lexical é outro aspecto que não exibe características de gradualidade; por sua vez, a estrutura entonacional parece prestar-se bem a análises probabilísticas.

Ainda no que concerne a modelos que defendem maior incorporação de informação fonética, a fonologia articulatória concebe os sons como constelações de gestos, cada gesto ocupando dimensões espaciais e temporais próprias, de modo que a sobreposição de articulações possa ser explicada de forma bastante simples (Browman e Goldstein, 1992). Por outro lado, aos gestos também é atribuído um caráter discreto, sem, contudo, abrir mão de idéias representacionais da fonologia. Como aponta Silva (2003), o modelo permite dar conta das alofonias contínuas, i.e., casos que envolvem não apenas duas ou mais categorias, mas um contínuo físico entre duas categorias extremas. Além disso, o modelo fornece aparato descritivo para outros casos que, de certa forma, constituem problemas para a geometria de traços: a) segmentos complexos, como, por exemplo, as consoantes prénasalizadas, e b) o desenvolvimento de segmentos intrusivos, como, por exemplo, o surgimento de /b/ na formação umeru $>>$ umru $>>$ ombro.

A OT começaria a ser adotada pelos pesquisadores brasileiros a partir do final dos anos 90; um dos primeiros textos a circular foi um artigo de Lee (1999) sobre a sílaba do português. Mais tarde, seguiriam estudos sobre o acento (Lee, 2001, Magalhães, 2008, Abaurre et al, 2006), sândi (Bisol, 2003), e sobre a realização das vogais átonas (Bisol e Magalhães, 2004). Na área de aquisição, diversos trabalhos buscam entender como o ranking do português é adquirido pelas crianças e como o ranking de línguas como o inglês é adquirido por falantes do português (Ferreira-Gonçalves, 2009;

\footnotetext{
${ }^{3}$ Para uma revisão, veja-se Cristófaro Silva (2006).
} 
Alves, 2009). A OT é por vezes duramente criticada pela forma avassaladora com que se instalou nos centros de pesquisa e nas editorias de revistas importantes da área. Sobre isso, uma reflexão antropológica mais ampla poderia ser feita; entretanto, uma das razões que parece ter sido importante foi a disponibilização dos textos em um arquivo/banco on-line, facilmente acessível a pesquisadores de todo o globo. Ainda que as publicações no arquivo da Universidade Rutgers não tenham o mesmo status de artigos publicados em renomadas revistas, seu impacto é inegável e permitiu um grande impulso nas produções em língua inglesa por pesquisadores brasileiros.

Estudos na linha da fonologia de exemplares e a fonologia de uso têm sido realizados por Cristófaro Silva e colaboradores, enfocando principalmente fenômenos de variação lingüística. Estas pesquisas têm revelado detalhes fonéticos, microvariações, que podem levar a mudanças, e revelam as relações estreitas que há entre percepção e produção. Além disso, estas pesquisas desenvolvem aplicação de programas computacionais para modelagem das mudanças.

A fonologia articulatória foi adotada e ganhou desenvolvimentos com o trabalho de Albano (2001) e Silva (2003). Albano (2001) propõe reformulações, como a inclusão de um buffer fonológico para a consideração de informações de caráter acústico. Questões como nasalização e coarticulações entre vogal e consoante - relação não prevista pela fonologia convencional - recebem análises sob esta perspectiva.

Os desenvolvimentos mencionados anteriormente não esgotam os modelos teóricos propostos, buscamos tão somente trazer aqui algumas das manifestações mais representativas.

\section{A FONOLOGIA DO PORTUGUÊS}

Nesta segunda parte, procuraremos descrever alguns dos trabalhos que contribuíram para a compreensão dos padrões sonoros do português; neste resgate, propomos tentativamente alguns dos miolos do conhecimento acumulado sobre o português.

\subsection{OS SONS DO PORTUGUÊS E SUA ORGANIZAÇÃO SISTÊMICA}

O inventário sonoro do português é bastante uniformemente aceite, com algumas áreas de discussão. No que se refere aos sons de r, uma das questões é se seriam dois fonemas ou um somente, questão que já tinha pautado 
diversas reflexões de Câmara Jr. (1953, 1970). Monaretto (1994) retoma para o português a idéia de Harris (1983) de que apenas or fraco faça parte do sistema, sendo o $r$ forte derivado contextualmente, de uma geminada, quando em contexto intervocálico ou de um processo de reforçamento, quando em posição inicial. Abaurre e Sândalo (2003) defendem que, pelo contrário, o português tenha apenas a vibrante no sistema e não o tepe. Miranda (1996, 2009), por sua vez, tem defendido a existência de dois segmentos róticos, com base em dados de aquisição da linguagem. Um consenso que emerge destes trabalhos é que o status dos róticos não se define no nível segmental, ou, melhor dizendo, não se define apenas no nível segmental, mas tem de englobar o nível silábico e níveis prosódicos mais amplos.

As vogais nasais e os ditongos nasais são outro ponto polêmico do inventário, mas há, de certa forma, um consenso de que, embora superficialmente se observem apenas as vogais nasalizadas, em algum nível de representação mais abstrato, haja duas unidades: uma vogal e um segmento nasal (seja um segmento N debucalizado (Battisti, 1997; Bisol, 1998), seja um segmento nasal pleno).

Outros segmentos polêmicos quanto ao seu papel no sistema são as palatais, tanto a nasal quanto a lateral. A distribuição limitada destes segmentos, restritos ao início de sílabas internas à palavra, levanta dúvidas sobre seu real valor contrastivo. Wetzels (2000) defende que as palatais [ñ] e $[\lambda]$ sejam segmentos geminados, baseado em argumentos como o fato de não poderem ser precedidas por rima pesada e terem o efeito de atribuírem peso à sílaba precedente.

O português - como outras línguas românicas - caracteriza-se por processos de harmonização de altura das vogais. Uma das questões em pauta é a caracterização dos diversos fenômenos de harmonia em termos de traços distintivos. Para Wetzels (1992), os diversos fenômenos de harmonia vocálica caracterizam mudança em uma única dimensão: a abertura da cavidade oral. Outros acreditam que os fenômenos sejam mais bem caracterizados através de um conjunto de traços de altura combinado com um traço referente à posição da raiz da língua [ATR] (Advanced Tongue Root), traço utilizado para a caracterização da harmonia nas línguas banto (Nevins, 2007). A questão é diretamente relacionada ao tema dos universais em termos de constituição de traços; por isso, considero importante destacála aqui, embora ainda não se possa falar em consenso neste caso.

As pesquisas relativas aos fenômenos de harmonia revelaram que o contraste entre vogais médias altas e baixas tem escasso aproveitamento 
na fonologia do português brasileiro, uma constatação que tem relevância estreita com a discussão teórica atual que se faz com relação ao papel do contraste nas línguas e da sua adequada expressão (Steriade, 2007). Com relação à elevação das vogais médias pretônicas, por harmonia com a vogal tônica, como em pedido, por exemplo, a contribuição dos estudos refere-se à discussão sobre o caráter dos processos de mudança, se implementados lexicalmente (difusão lexical) ou por mudança automática (neogramática).

\subsection{ESTRUTURA SILÁBICA}

A sílaba é talvez uma das unidades mais genuinamente fonológicas. Do ponto de vista fonético, sua definição adequada é praticamente impossível. Do ponto de vista fonológico, há consenso que o falante tem um conhecimento implícito da sílaba, que usa em muitos aspectos na língua falada, como quando tenta encaixar texto em uma melodia. Pesquisas de caráter psicolingüístico sugerem que qualquer falante tem acesso à noção de sílabas, mesmo os falantes não-letrados (Morais, 1996).

Ao longo da década de 80, a sílaba foi ganhando autonomia, adquirindo status de constituinte autônomo, com nível representacional próprio. A sílaba foi invocada para explicar: a distribuição dos segmentos na palavra; as regularidades do posicionamento do acento; as regularidades do posicionamento do tom nas palavras (em línguas tonais); a aplicação de determinados processos fonológicos, tais como substituição de um segmento por outro, apagamento e inserção de segmento e troca de posição de segmentos entre si.

A estrutura silábica estimulou diversas pesquisas sobre o português, tanto no que se refere às condições que regem a organização das sílabas na língua (Bisol, 1999, Lee, 1999), quanto ao seu papel na aquisição da linguagem (Lamprecht, 2004, e outros), bem como no que se refere a processos que se explicam com base na distribuição dos segmentos em determinadas posições silábicas.

Quanto a este último tópico, trabalhando com processos de lenição variável no português brasileiro, Leite, Callou e Moraes (2002) propõem que estaria em curso uma mudança no sentido de tornar as sílabas fechadas (CVC) em abertas (CV) no português brasileiro. Outros estudos sobre o processo de epêntese vocálica mostram que o português brasileiro, diferentemente do português europeu, insere um segmento vocálico para 
evitar encontros de obstruintes, como em pa[ki]to (pacto), ou para evitar obstruintes em final de palavra, como em pa[ki] $(P A C)$, por exemplo. A realização de epêntese na aquisição de LE também foi tema de diversas pesquisas (Alves, 2009; Cardoso, 2007). Além disso, simplificações em onset foram também objeto de descrição, especialmente na aquisição de língua materna (Lamprecht, 2004) e na aquisição de LE. O que essas pesquisas têm em comum é o emprego da noção de marcação no que se refere aos tipos silábicos e a interpretação de que, por trás dos processos analisados, existe uma tendência comum no português brasileiro no sentido de simplificação da complexidade silábica.

Outro aspecto que mereceu análises foi a representação dos glides (Bisol 1994). Em geral, considera-se que os glides sejam realizações derivadas de vogais e, eventualmente, de consoantes com articulação secundária vocálica (como a lateral pós-vocálica velarizada e a lateral palatal). Entretanto, alguns casos têm de ser tratados como glides subjacentes. Por exemplo, em palavras como água e quase, não se pode dizer que a semivogal seja derivada de uma vogal fonológica, pois essa vogal nunca se realiza como vogal plena. Portanto, o português fornece evidências contra a tese de que o status de glides seja exclusivamente determinado pela estrutura silábica da língua. ${ }^{4}$

No nível da frase, freqüentemente, ocorrem alterações da estrutura silábica atribuída em nível da palavra. Por exemplo, no português, temos reestruturações nas fronteiras entre palavras, que, muitas vezes, alteram a estrutura silábica original, mas que obedecem aos requisitos vigentes na estruturação silábica em nível de palavra. Por exemplo, na expressão faixa etária, a vogal final da primeira palavra é comumente elidida, resultando a seqüência faix[e] tária..$^{5} \mathrm{~A}$ análise de hiatos e ditongos na estrutura frasal mostra que a língua otimiza a estrutura silábica desde que respeitados os segmentos que carregam o acento tonal, e essa determinação de cima para baixo, da estrutura tonal para a estrutura silábica e segmental, é um dos aspectos da língua que desafiam os modelos teóricos da fonologia prosódica, que, via de regra, somente admitem a determinação de baixo para cima.

\footnotetext{
${ }^{4}$ Bisol (1994) adota a solução de que este glide seja proveniente de uma articulação secundária das consoantes $/ \mathrm{k}^{\mathrm{w}} / / \mathrm{g} /$, lexicalmente especificada.

${ }^{5} \mathrm{O}$ exemplo foi observado por mim num processo de correção de prova de redação, em que mais de um candidato transcreveu a expressão como fachetária.
} 


\subsection{ACENTO}

No que se refere ao acento lexical, há, inicialmente, três fatos a considerar: i) o acento somente pode cair sobre uma das três últimas sílabas; ii) dessas três, há uma preferência pelo acento na penúltima; e iii) nos nãoverbos, há preferência pela última sílaba quando ela for pesada. Na década de 70, a descrição desses fatos foi proposta com regras que atribuíam o traço [+acento] às vogais (Leite, 1974, Lopez, 1979, Mateus, 1982). Estas abordagens davam conta das generalizações acima, mas não tinham como explicá-las. A fonologia métrica trouxe a idéia de que o acento depende crucialmente das sílabas e de que há unidades menores do que a palavra que organizam a estrutura acentual, os pés ou constituintes métricos. As análises métricas, ao adotarem esses constituintes e a noção de peso silábico, avançaram na explicação sobre as propriedades do acento em português e ajudaram a revelar novas questões e problemas.

Uma das questões que vem suscitando debates é se o padrão de acento de verbos pode ser explicado pelo mesmo padrão de acento dos nomes, ou se é de outra natureza. Bisol (1992) propõe a existência de um padrão só, com extrametricidade específica para os verbos. Massini-Cagliari (1999) defende esse mesmo padrão para o português arcaico. Lee (1994) propõe dois padrões, um para verbos - com proeminência trocaica - e outro para os nomes - com proeminência à direita no domínio do radical. Nesta abordagem, a última sílaba dos nomes fica fora do domínio de acento, razão por que as vogais temáticas são consistentemente átonas nos nomes. A discussão das diversas propostas revelou que o acento é condicionado por fatores fonológicos combinados com fatores morfológicos.

Outra questão refere-se à integração das palavras proparoxítonas na análise geral. Normalmente, devido ao pequeno número de palavras primitivas proparoxítonas, o seu acento é tratado como lexicalmente especificado (Bisol, 1992, Massini-Cagliari, 1999, Magalhães, 2004). Entretanto, a língua não é refratária a novas formações, através de sufixos como -ico, -íssimo, por exemplo. Isso mostra que somente a marcação de itens lexicais não basta para dar conta do acento proparoxítono, mas que outro mecanismo que permita gerar a excepcionalidade no componente morfofonológico deve estar previsto. Outra constatação que tem sido feita é que a relação entre acento e qualidade vocálica não precisa ser necessariamente unidirecional, com a localização do acento determinando a qualidade das vogais: o acento também parece ser sensível à qualidade das vogais (Sandalo, 1999, Bonilha, 2004). 
A fonologia métrica permitiu a identificação de padrões na estrutura acentual da língua, que antes ficavam obscurecidos pelo mecanismo formal das regras. A Teoria da Otimalidade permitiu avançar na análise, mostrando que padrões que, à primeira vista, parecem contraditórios, podem ser explicados com base em restrições antagônicas em competição. A Teoria da Otimalidade contribuiu também para desenvolver a ideia de que os padrões de acento de uma língua podem refletir a interrelação entre condições fonológicas e morfológicas; aquilo que, em modelos anteriores, era tratado simplesmente como excepcional, agora pode ser integrado em um modelo que admite maior complexidade sem abrir mão da explanação do conjunto dos padrões.

\subsection{INTERAÇÃO FONOLOGIA E MORFOLOGIA}

A interação entre fonologia e morfologia apresenta-se em três modalidades: i) no nível mais abstrato da fonologia, a morfologia pode exercer papel condicionante de processos fonológicos; ii) no nível mais superficial da fonologia, a estrutura morfossintática contribui para a determinação dos constituintes prosódicos dentro dos quais os processos fonológicos são aplicados, e iii) num determinado tipo de formação morfológica, muitas vezes chamada genericamente de morfologia não-concatenativa, a fonologia, no que se refere à estrutura prosódica, pode exercer papel condicionador da estruturação morfológica

Dentro da primeira modalidade, as contribuições mais significativas são as que se referem à harmonia, ou metafonia, vocálica em nomes e verbos (Miranda, 2002 Wetzels, 1991), trabalhos que revelam as possibilidades da análise autossegmental dos processos assimilatórios, em termos de processo de neutralização e de subespecificação de traços. Além disso, esses trabalhos revelam o papel do pé de acento nesse tipo de especial de fenômeno de assimilação regressiva, em que a vogal acentuada perde sua especificação para uma vogal desacentuada (ex. 'pOvo > 'povo), embora não haja ainda um consenso sobre a explanação adequada desse fato.

Quanto à segunda modalidade, um pressuposto fundamental da Fonologia Prosódica (Nespor e Vogel, 1986) é o de que, para cada expressão linguística, há uma segmentação prosódica ao lado de uma segmentação sintática, ou, mais propriamente, morfossintática. Embora os constituintes prosódicos sejam mapeados a partir dos constituintes morfossintáticos, 
não há necessariamente isomorfismo entre eles, ou seja, um constituinte sintático pode ser mapeado sobre mais (ou menos) de uma unidade prosódica correspondente. Assim, a representação prosódica seria um nível intermediário (o qual tem acesso direto à sintaxe, mas filtra uma série de informações e reajusta os limites de domínios determinados pela sintaxe) de forma a produzir os domínios a que as regras fonológicas têm acesso. A partir desta proposta teórica, algumas tarefas se impõem: (a) verificar como se realiza o mapeamento de diferentes estruturas morfossintáticas em palavras prosódicas em português; (b) verificar que processos fonológicos trazem evidência para constituintes como a palavra prosódica e a frase fonológica. No português, constata-se que prefixos podem constituir palavras prosódicas independentes, bem como sufixos especiais, como -mente e zinho, e os membros de compostos (por exemplo, toca-discos), embora não sejam morfologicamente palavras independentes (Schwindt, 2001, Vigário, 2003, Bisol, 2004). Hátambém contribuições das investigações sobre a aquisição da escrita para o reconhecimento, por parte do falante, dos desencontros entre unidades morfossintáticas e prosódicas, a exemplo de hipossegmentações como sesquecer e ubluzão, para, respectivamente, se esquecer e o blusão (Chacon, 2004; Miranda, 2009).

Quanto à terceira modalidade, as pesquisas sobre formação de palavras por truncamento, como em vestiba, de vestibular, por exemplo, relacionam a estrutura produzida com a estrutura prosódica. Em muitas línguas, podese reconhecer neste processo o papel do pé métrico comum na língua. Por exemplo, em profe, de professora, a forma que se obtém resulta da eliminação do pé trocaico de acento e, com as sílabas que sobram, formase um novo pé, com mudança na posição do acento. Esse e outros padrões de truncamento no português são estudados por Gonçalves (2009) e, por sua vez, contribuem com evidências para o pé troqueu como o pé métrico default do português.

\subsection{ACENTO FRASAL E ENTONAÇÃO}

$\mathrm{O}$ acento secundário foi objeto de muita pesquisa experimental, tanto no que se refere às propriedades acústicas que lhe seriam correlatas (Moraes, 2003), quanto à sua percepção por parte dos falantes (Sândalo e Abaurre, 2007). Uma das questões que foram debatidas pelas pesquisas é se o acento secundário do português brasileiro se explica por uma organização rítmica binária $\mathrm{da}(\mathrm{s})$ proeminência(s) secundária(s) ou se 
simplesmente reflete o alinhamento à esquerda de uma proeminência com a palavra prosódica, como no português europeu (Vigário, 2003). O que se constata, dos levantamentos realizados, é que o acento secundário do português brasileiro não pode ser explicado exclusivamente com base na proeminência inicial (hipótese do alinhamento à esquerda), ou seja, parece haver um padrão rítmico de alternância binária. Essa constatação tem relação com a questão muito debatida também se o português seria uma língua syllable-timed ou stress-timed. O consenso atual parece ser o de que, que embora o português não seja prototipicamente syllable-timed, está muito mais próximo de línguas que têm este caráter, como o espanhol, por exemplo, do que do português europeu, que tende a ser mais stress-timed. Há também um consenso atual de que a classificação definitiva de uma língua dentro de uma categoria ou outra não seja possível, com o que essa distinção vem aos poucos sendo substituída.

Sobre o choque de acentos e a resolução por retração de acento, as pesquisas concentraram-se em verificar o papel dos constituintes prosódicos, especialmente da frase fonológica. Tenani (2002) constata que a retração de acento ocorre quando o choque for interno a uma frase fonológica (como em [chegou tarde]), mas não quando ocorrer na fronteira entre frases (como em [para contar] [minha história]). Santos (2002) e Sandalo e Trukenbrodt (2004) avaliam o papel de propriedades sintáticas que são levadas em conta na constituição das frases fonológicas e seu reflexo na retração de acento. Todos estes trabalhos baseados no julgamento dos falantes concordam que há uma propriedade acentual que ocorre internamente às frases fonológicas e que não ocorre da mesma maneira em contextos de fronteira de frase. Outro questionamento é se o que ocorre é realmente uma retração de acento, de chegou para chegou, por exemplo, ou se se trata de desacentuação. Com base em análise acústica de contextos de choque, Barbosa e Arantes (2003) não encontraram evidências de retração, por exemplo, em termos de duração; entretanto, esses autores observaram a possibilidade de uma mudança em um acento tonal. É uma questão em aberto se o que os falantes percebem é realmente uma retração de acento ou outra coisa, de base mais tonal. Para o inglês, por exemplo, a mudança de acento proposta por Liberman e Prince (1977) passou a ser reanalisada como apagamento de acento tonal (Gussenhoven, 2004, p. 141). Talvez se possa chegar a constatação similar para o português, a partir do avanço na análise da estrutura tonal das frases em português. 
Nas décadas passadas, as abordagens fonológicas da entonação convergiram com outros aspectos da teoria e descrição fonológica. Estes desenvolvimentos foram conseqüência da adoção do modelo autossegmental, uma concepção desenvolvida originalmente para tratar do tom lexical (Leben 1973, Goldsmith 1976). A análise autossegmental do tom implica que o contorno entonacional seja derivado a partir de níveis ou de unidades tonais e não seja um primitivo da teoria. Ainda que cada tipo de frase seja associada com um contorno tonal próprio (tune), esse 'canto' é, na verdade, uma série de unidades tonais combinadas. Além disso, a teoria diminuiu o número de distinções tonais: há apenas dois níveis, alto e baixo (High/ Low), e alguns elementos diacríticos que, combinados aos tons alto e baixo, podem resultar em realizações fonéticas intermediárias. Em conseqüência, a estrutura tonal de uma frase é, na verdade, caracterizada por alguns poucos acentos tonais e tons de fronteira, sendo o contorno melódico final obtido por interpolações fonéticas entre estes pontos tonais. Como reconhece Gussenhoven (2007), a consequência disso é uma relação muito menos direta entre a fonologia e fonética do que nas análises entonacionais anteriores, mas, em contrapartida, a compreensão do que caracteriza um contraste entonacional entre frases ficou muito mais próxima do que se entende por contraste em outras áreas da fonologia.

As pesquisas sobre estrutura tonal em português seguiram esse mesmo rumo, iniciando com uma preocupação em estabelecer os correlatos acústicos da entonação para depois buscarem, cada vez mais, entender e descrever as unidades que a caracterizam. Moraes (1993) apresenta uma descrição de aspectos da entonação do português em termos de contornos melódicos e aponta para informações fonéticas importantes para a detecção da entonação e para aquelas que parecem não ter papel na análise. Madureira (1999) traz para a discussão os diferentes tipos de abordagens para a entonação e defende uma abordagem que contemple um componente fonológico interligado a um componente fonético da entonação. A disseminação dessa concepção mais paramétrica dos sistemas entonacionais, aliada ao aperfeiçoamento dos programas de análise acústica, em muito contribuiu para o desenvolvimento de um trabalho mais colaborativo entre pesquisadores de diferentes línguas, tanto que hoje se observam grupos internacionais de pesquisa dos sistemas tonais das línguas românicas e germânicas, entre outros (D'Imperio et al, 2005).

Graças a estes desenvolvimentos, já podemos encontrar hoje descrição das características básicas da entonação do português brasileiro: Frota 
\& Vigário (2000) e Tenani (2002) identificam o contorno tonal das sentenças declarativas como sendo determinado por um acento tonal $\mathrm{H}+\mathrm{L}^{\star}$ associado ao núcleo da frase fonológica mais à direita; Moraes $(2007,2008)$ apresenta uma descrição detalhada de diversos contornos entonacionais, combinando acentos tonais, tons de fronteira e acentos pré-nucleares, e Fernandes (2007) apresenta uma descrição do efeito do foco sobre a estrutura tonal. Ainda muitas questões se colocam, tais como a distinção entre diferenças alofônicas e o contraste tonal propriamente dito, a relação entre o fraseamento prosódico e a entonação e o foco, os limites das categorias entonacionais gramaticais propriamente ditas e outros significados veiculados pela entonação. Além disso, é evidente que uma nova área de investigação se abre para os próximos anos, no que diz respeito às variedades do português brasileiro e às diferenças entonacionais entre o português brasileiro e variedades portuguesas africanas e européias. O tema da entonação recebeu inúmeras abordagens, nem todas as quais consideradas aqui. Vale dizer que o tema enriquece a disciplina de fonologia por permitir novas abordagens cooperativas entre foneticistas e fonológos, e também o trabalho transdisciplinar com a engenharia lingüística, a psicolingüística e áreas de análise da conversa e do discurso. Além de denominadores comuns que vêm sendo assentados no trabalho descritivo, acredito que uma das convicções que vêm tomando força é que a análise acústica de uma sentença não fornece diretamente a sua estrutura entonacional, mas somente indiretamente, através da estrutura prosódica abstrata das unidades fonológicas do nível tonal.

\section{PARA FINALIZAR}

Impossível resumir todas as descobertas a que se chegou nos últimos 25 anos em tão poucas linhas. Aos que começam a estudar a língua nos aspectos fonético e fonológico, tentamos contar um pouco do que aconteceu, dos embates das idéias e das observações e constatações a respeito das propriedades características do português. Esperamos que o relato aqui apresentado possa ter espelhado em alguma medida a aventura fascinante que é o estudo sistemático e cientificamente embasado da nossa língua materna e possa ter revelado a importância que o conhecimento sobre a nossa língua tem para o entendimento do funcionamento da linguagem humana em geral. 


\section{REFERÊNCIAS BIBLIOGRÁFICAS}

ABAURRE, M. B. M. ; GALVES, C. ; MANDEL, A. ; SANDALO, F. . Secondary stress in two varieties of Portuguese and the sotaq optimality based computer program.. Probus (Dordrecht), v. 18, 2006. p. 97-125.

ABAURRE, M. B.; SANDALO, F. S. Os róticos revisitados. In: HORA, D. da; COLLISCHONN, G. (orgs.) Teoria Lingüística. Fonologia e outros temas. João Pessoa: Ed. da UFPB, 2003.

ALBANO, E. C. O gesto e suas bordas: esboço de Fonologia AcústicoArticulatória do português brasileiro. Campinas: Mercado de Letras; ALB; Fapesp, 2001.

ALVES, U. K. Os dados de aquisição de L2 e sua relação com a Teoria Fonológica: reflexão a partir de uma análise via OT. In: FERREIRAGONÇALVES, Giovana; KESKE-SOARES, Márcia; BRUM-DE-PAULA, Mirian. (Org.). Estudos em Aquisição Fonológica - volume 2. Santa MariaRS: Sociedade Vicente Pallotti, v. 2, 2009. p. 165-179.

ANDERSON, J. M.; EWEN, C. J. Principles of Dependency Phonology. Cambridge:

Cambridge University Press, 1987.

ARAÚJO, G. A. O acento em português: Abordagens fonológicas. São Paulo: Parábola, 2007

BARBOSA, P. A., ARANTES, P.. 2003. Investigation of non-pitchaccented phrases in Brazilian Portuguese: no evidence favoring stress shift. In: Proceedings of the XVth International Congress of Phonetic Sciences. Barcelona: XVth International Congress of Phonetic Sciences, 2003.

BECKMAN, M ; KINGSTON, J. (eds.) Papers in Laboratory Phonology, Cambridge: Cambridge University Press, 1990.

BISOL, L. e MAGALHÃES, J. S. de. A redução vocálica no Português Brasileiro: avaliação via restrições. Revista da ABRALIN, vol. III, nos. 1 e 2, 2004, p. 195-216,. 
BISOL, L.. Mattoso Câmara Jr. e a palavra prosódica. D.E.L.T.A., v. 20 (especial), 2004. p. 59-70.

. A sílaba e seus constituintes. In: NEVES, M. H. M. (Org.) Gramática do português falado. v.VII. São Paulo: Humanitas/FFLCH/ USP; Campinas: Ed. Unicamp, 1999.

. O acento e o pé métrico binário. Caderno de Estudos Lingüísticos, n. 22, 1992. p. 69-80.

. O sândi e a ressilabação.. Letras de Hoje, v. 31, n. 2. 1996, p. $159-168$.

. Sandhi in Brazilian Portuguese. Probus, 15, 2003. p. 177-200.

. A Nasalidade, um Velho Tema. DELTA, v.14, no.spe, 1998.

. Ditongos derivados. DELTA. Vol. 10, 1994. p. 123-140.

BOERSMA, P; WEENINK, D. Praat, a system for doing phonetics by computer, version 3.4. Institute of Phonetic Sciences of the University of Amsterdam, Report 132. 182 p.

BONILHA, G. F. G. A influência da qualidade da vogal na determinação do peso silábico e formação dos pés: o acento primário do português. Organon UFRGS, v. 18, n. 36, 2004. p. 41-56.

BROWMAN, C.P. and GOLDSTEIN, L. Articulatory phonology: an overview. Phonetica, n. 49, v. 3-4, 1992. p. 155-180.

BROWMAN, C.P. and GOLDSTEIN, L. Towards an articulatory phonology. In C. Ewen and J. Anderson (eds.) Phonology Yearbook 3. Cambridge: Cambridge University Press, 1986. p. 219-252.

CÂMARA JR., J. M. Para um Estudo da Fonêmica Portuguesa. Rio de Janeiro: Organização Simões, 1953.

. Estrutura da língua portuguesa. Petrópolis: Vozes, 1970.

CAGLIARI, L. C. Fonologia do Português: análise pela geometria de traços. v. 2, Campinas: Edição do Autor, 1997. 
CARDOSO, W. The variable development of English word-final stops by Brazilian Portuguese speakers: A stochastic optimality theoretic account. Language Variation and Change, v. 19, Issue 03, 2007. p. 219-248.

CHACON, L. Constituintes prosódicos e letramento em segmentações não-convencionais. Letras de Hoje, v. 39, n. 3, 2004. p. 223-232.

CLEMENTS, G N.; KEYSER. S. J. CV Phonology: A Generative Theory of the Syllable. Cambridge: MIT Press, 1983.

CLEMENTS, G. Vowel Harmony in Nonlinear Generative Phonology. Indiana University Linguistics Club: Bloomington, 1976.

. The geometry of phonological features. Phonology Yearbook 2. 1985. Cambridge: Cambridge University Press. p. 225-252.

CRISTÓFARO SILVA, Thaïs . Fonética e Fonologia: Perspectivas Complementares . Revista Estudos da Linguagem, Vitória da Conquista, v. 3, 2006. p. 25-40.

. On Branching Onsets in Brazilian Portuguese. Revista de Estudos da Linguagem, Belo Horizonte, 2002.

D'IMPERIO, M.; ELORDIETA, G.; FROTA, S.; PRIETO, P.; VIGÁRIO, M. Intonational phrasing in Romance: The role of syntactic and prosodic structure. In: Frota, S.; Prieto, P.; Vigário, M; Freitas, M. J. Prosodies. Berlin \& New York: Mouton de Gruyter, 2005. p . 59-97.

DINNSEN,D.A.(1985). A re-examination of phonological neutralization. Journal of Linguistics, 21, 265-279

FERREIRA-GONÇALVES, G . Unidades prosódicas sílaba e acento no processo de aquisição da linguagem. In: Ferreira-Gonçalves, G; Keske-Soares, M.; Brum-de-Paula, M.R. (Org.). Estudos em Aquisição Fonológica v. 2. Santa Maria: Pallotti, 2009. p. 184-203.

FERNANDES, F. R. Tonal association of neutral and subject-narrowfocus sentences in Brazilian Portuguese: a comparison with European Portuguese. Journal of Portuguese Linguistics. v. 5/6, 2007. p. 91-115.

FROTA, S. Prosody and focus in European Portuguese. Tese de doutorado. Universidade de Lisboa, 1998. 
GOLDSMITH, J. Autosegmental Phonology. MIT dissertation, Distribuído por Indiana University Linguistics Club, 1976 Disponível em http://hum.uchicago.edu/ jagoldsm/Papers/dissertation.pdf

. Theory, Kernels, Data, Methods. Trabalho apresentado no 17th Manchester Phonology Meeting. Manchester. 2009. Disponível em http://hum.uchicago.edu/ jagoldsm/Webpage/index.html

GOLDSMITH, J.; LAKS, B. Generative phonology: its origins, its principles, and its successors. In: Linda WAUGH, L.; JOSEPH, J. E. (orgs.) The Cambridge History of Linguistics (no prelo)

GONÇALVES, C. A. V. Retrospectiva dos estudos em Morfologia Prosódica: das circunscrições e regras à abordagem por ranking de restrições. Alfa (ILCSE/UNESP), v. 53, 2009. p. 195-221.

GUSSENHOVEN, C. Intonation. In: LACY, P. de (ed.) The Cambridge Handbook of Phonology. Cambridge: Cambridge University Press, 2007.

HARRIS, J. Syllable structure and stress in Spanish. Cambridges: MIT Press, 1983.

HERNANDORENA, C. L. M. Sobre a descrição de desvios fonológicos e de fenômenos da aquisição da fonologia. Letras de Hoje, Porto Alegre, v. 30, n. 4 , p.

HERNANDORENA, C..L.M. A Geometria de Traços na Representação das Palatais na Aquisição do Português. Letras de Hoje. Porto Alegre. v. 29, n. 4, 1994. p.1-167.

HORA, D. da .A Palatalizacao das Oclusivas Dentais: Uma Abordagem Nao Linear. D.E.L.T.A., v. 9, n. 2, 1993. p. 175-193.

KAYE, J.; LOWENSTAMM, J.; VERGNAUD, J. R.. The internal structure of phonological representations: a theory of Charm and Government. Phonology Yearbook 2, 1985. Cambridge: Cambridge University Press. p. 305-328.

LABOV, W. The social stratification of English in New York City. Washington DC: Center for Applied Linguistics, 1966. 
. Principles of linguistic change - internal factors. Malden/Oxford: Blackwell, 1994.

LAMPRECHT, R. R.. Antes de mais nada. In: Regina Ritter Lamprecht. (Org.). Aquisição fonológica do Português. Porto Alegre: Artmed Editora, 2004. p. 17-32.

LEBEN, W. R. Suprasegmental phonology. Doctoral dissertation. Cambridge/MA: MIT, 1973.

LEE, S.H. A regra do acento do português: outra alternativa. Letras de Hoje, Porto Alegre, 1994. p. 37-42.

. Teoria de Otimalidade e silabificação do PB. In: IBLER, V. B; MENDES, E.; OLIVEIRA, P. F.M. de (ed.). Revisitações. Edição Comemorativa dos 30 anos da FALE/UFMG. Belo Horizonte: UFMG, 1999. p 143-156.

LEITE, Y. Portuguese stress and related rules. Tese de doutorado. Austin, University of Texas, 1974.

LEITE, Y. F., CALlOU, D. M. I., MORAES, J. A. Processos de enfraquecimento consonantal no português do Brasil. In: Gramática do Português Falado. 1 ed. Campinas: Ed. da UNICAMP, 2002.

LOPEZ, B. S. The sound pattern of Brazilian Portuguese (Cariocan dialect). Los Angeles: UCLA. Tese de doutorado. University Microfilms International, 1979.

MAGALHÃES, J. S. O Acento dos Não Verbos no Português Brasileiro no Plano Multidimensional. Alfa (ILCSE/UNESP), v. 52, 2008. p. 405430 .

MAGALHÃES, J. O. Aspectos fonológicos segundo a Teoria do Charme e do Governo: padrão silábico e sílaba máxima. Letras de Hoje, Porto Alegre, v. 98, 1994. p. 113-128.

MATEUS, M. H. M. Aspectos da Fonologia Portuguesa. Lisboa: Instituto Nacional de Investigação Científica, 1982. 
MCCARTHY, J. J.; PRINCE, A.. Faithfulness and identity in prosodic morphology. In: KAGER, R.; HULST, H. van der; ZONNEVELD, W. The Prosody-Morphology Interface. Cambridge: Cambridge University Press, 1999. p. 218-309.

MIRANDA, A. M.; CUNHA, A. P. N. A hipo e a hipersegmentção nos dados de aquisição de escrita: a influência da prosódia. Alfa, São Paulo, v. 53, n. 1, 2009. p. 127-148.

MIRANDA, A. M. A metafonia nominal (português do Brasil). Letras de Hoje, v. 37, n. 1, 2002. p.69-98.

MONARETTO, V. O status fonológico da vibrante. Letras de Hoje, n. 98, 1994. p. 153-157.

MORAES, J. A. The Pitch Accents in Brazilian Portuguese: analysis by synthesis. In: Fourth Conference on Speech Prosody. Proceedings of the Speech Prosody 2008. Campinas: Unicamp, 2008. p. 389-397.

. Intonational Phonology of Brazilian Portuguese, ms. Apresentado no Workshop on Intonational Phonology: understudied or fieldwork languages, ICPhS 2007 Satellite Meeting, Saarbrücken, 5/08/2007.

. A Entoação Modal Brasileira: Fonética e Fonologia. Cadernos de Estudos Lingüisticos (UNICAMP), Campinas, v. 25, p. 101-111, 1993.

NESPOR, M.; VOGEL, I. Prosodic Phonology. Dordrecht: Foris, 1986. Traduzido como La prosodia. Tradução de Ana Ardid Gumiel. Madrid: Visor, 1994.

NEVINS, A. Review of Jonathan Barnes' Strength and Weakness at the Interface: Positional Neutralization in Phonetics and Phonology. Phonology v. 24 n. 3, 2007. p. 461-469.

PIERREHUMBERT, J. Exemplar dynamics: word frequency, lenition, and contrast. In: J. Bybee \& P. Hopper (eds.), Frequency effects and the emergence of linguistic structure. Amsterdam: John Benjamins. 2001. p. 137-157.

. Word-specific phonetics. In GUSSENHOVEN, C. ; WARNER, N. (eds.). Papers in Laboratory Phonology VII. Berlin: Mouton de Gruyter, 2002. p. 101-140. 

MIT, 1980.

The phonology and phonetics of English intonation. $\mathrm{PhD}$ thesis,

PINTZUK, S. Varbrul programs. Philadelphia: University of Pensnsylvania, 1988. Manuscrito

PORT, R. F.; CRAWFORD, P. Incomplete neutralization and pragmatics in German. Journal of Phonetics 16, 1989. p.257-282

PRINCE, A.; SMOLENSKY, P. Optimality Theory: Constraint Interaction in Generative Grammar, 1993. Disponível em http://www.rutgers.edu.

ROUSSEAU, P. \& D. SANKOFF Advances in variable rule methodology. In: SANKOFF, D. (ed.). Linguistic variation: models and methods. New York: Academic Press, 1978. p. 57-68.

SANDALO, F. ; TRUCKENBRODT, H. Some notes on Phonological Phrasing in Brazilian Portuguese. DELTA, 2004.

SANKOFF, D. Variable rules. In: AMMON, U., N. DITTMAR \& K.J.MATTHEIER (eds.) Sociolinguistcs - an intemational handbook of the science of language and society. Berlin/New York: Walter de Gruyter, 1988. p. 984-998.

SANTOS, R. S. O acento e a aquisição da linguagem em português brasileiro. In: Araújo, Gabriel Antunes. (Org.). O acento em português: abordagens fonológicas. São Paulo: Parábola, 2007, v. 1, p. 225-258.

SCHWINDT, L. C. O prefixo no português brasileiro: análise prosódica e lexical. DELTA, v. 17, n. 2, 2001.

SILVA, A. H. P. Pela incorporação de informação fonética aos modelos fonológicos. Revista Letras, Curitiba, n. 60, 2003. p. 319-333.

SJÖLANDER, K.; BESKOW, J. WAVESURFER. Department of Speech, Music and Hearing, Centre for Speech Technology. 2006. http://www. speech.kth.se/wavesurfer/

STERIADE, D. Contrast. In: DE LACY, p. (org.) The Cambridge Handbook of Phonology. Cambridge University Press, 2007. 
TENANI, L. Domínios prosódicos no português do Brasil: implicações para a prosódia e para a aplicação de processos fonológicos. Tese de doutorado. Universidade Estadual de Campinas, 2002.

VAUX, B.; NEVINS, A. Rules, Constraints, and Phonological Phenomena. Oxford, Oxford University Press, 2008. p.20-60.

VIGÁRIO, M.. The Prosodic Word in European Portuguese, Berlin \& New York:

Mouton de Gruyter, Interface Explorations 6, 2003. 440 p.

WETZELS, W. L. Consoantes palatais como geminadas fonológicas no Português Brasileiro. Revista de Estudos da Linguagem, v.9, n. 2, 2000. p. 5-15.

. Mid Vowel Neutralization in Brazilian Portuguese. Cadernos de Estudos Lingüísticos, v. 23, 1992. p.19-56.

.Harmonização vocálica, truncamento, abaixamento e neutralização no sistema verbal do português. Cadernos de Estudos Lingüísticos, v. 21, 1991. p.25-58. 
